\title{
Effect of an Intensive Hand Exercise Program on Knowledge, Hand Strength and Daily Living Activity among Rheumatoid Arthritis Patients
}

\author{
Thoraya Mohamed Abdelaziz, Assistant Professor \\ Medical Surgical Nursing, Faculty of Nursing, Alexandria University \\ Howida Khalaf Abd-Elaal, Professional Nurse \\ Nursing Development Trainer, Center of Technical Training and Nursing Development, \\ Assuit University Hospital, Assuit
}

\begin{abstract}
Rheumatoid arthritis $(R A)$ is an inflammatory polyarthritis disease that causes consistent joint pain, joint damage and disability. Generally $R A$ rehabilitative management goals are to prevent or control joint injury, improve function and reduce pain. Objective: Assess knowledge, hand strength and daily living activity among RA patients. Setting: The Rheumatology Department and Rheumatology Outpatient Clinic of Assiut University Hospital. Subjects: Fifty female adult patients with hand and wrist RA. Tools: Tool I: The Health Assessment interview schedule, tool II: Michigan Hand outcome Questionnaire, and tool III: Hand grip strength test. Results: A highly significant statistical improvement was detected in patients' knowledge regarding RA, also in the total scores of common daily activity, hand function and minimal hands/wrist pain. Conclusion: The intensive hand exercise program has a tangible improvement on Rheumatoid Arthritis female patients hand strength as well as their daily living activities. Recommendations: Written simple pictured booklet and pamphlets about RA and its management should be provided and available for patients.
\end{abstract}

Kevwords: Rheumatoid arthritis; Hands and wrist exercises; Rehabilitation program.

\section{Introduction}

Rheumatoid arthritis (RA) is an autoimmune disorder which mainly affects joints. RA is often has flares and remissions attacks. Joint complaints including pain and generalized stiffness throughout the day, may be present as the joint feels warm and/or tender, with a general feeling of fatigue. It classically affects small joints of the hands and the feet, on both sides equally in a symmetrical distribution. Over the time most of the synovial joints will be affected $^{(1,2)}$.

In spite no precise reports regarding the prevalence of RA in developed countries; its incidence is about 1.5 million people in the United States. It increases in the age group between 30 to 60 years, females are more prone to RA three times than males, RA prevalence varies between $0.3 \%$ and $1 \%$ in developed countries ${ }^{(3)}$. The frequency of RA foot involvement has been reported in approximately $16 \%$ of RA patients, while $80-90 \%$ of RA patients have hands and wrists affection. In $15 \%$ of cases the first symptomatic area is the forefoot and nearly $100 \%$ of patients report foot problems within 10 years of RA onset ${ }^{(2,4)}$.

Rheumatoid arthritis (RA) is a gradual progressive destructive inflammatory disease with loss of hand function and intraarticular complications; thus routine activities are difficult to perform, in turn affects the ability to fulfill social roles and obligations. Wrist involvement within 2 years of diagnosis is common in more than half of RA patients. It is thought to be less disability than RA of the fingers and hand; but it significantly can cause pain and disability $^{(4,5)}$.

The American college of rheumatology recommend clinical guidelines application for the management of RA through the use of physiotherapy (PT) and occupational therapy (OT) in addition to 
medication $^{(8)}$. The three most common components of PT/OT for RA hands are exercise therapy, joint protection instructions, functional immobilization and use of assistive devices ${ }^{(6)}$. Patient education is a multi-stage learning process, which is performed to increase patients ${ }^{\text {ee }}$ knowledge levels and to impact their health behavior positively by improving the activity of daily living (ADL) of patients with rheumatoid arthritis of hands. Thus, patients will be capable of control the disease, prevent its complications and manage $\mathrm{it}^{(7)}$.

Currently, RA management is symptomatic; therefore, patients are subjected to various life-long treatment modalities. Thus, successful management of the disease relies on educating patients and informing them about the planned treatment modalities.

Rehabilitation is usually defined as "Restoration of patients to their maximum physical, mental, and social abilities, within limits of disability". Rehabilitation is a set of interventions whereby patients are enabled to achieve as much as they can in the context of their disease limitations in everyday functioning due to ageing or a health condition. Objectives of RA patients' rehabilitation are to: prevent disability, increase functional capacity, relief pain and improve RA patients' activity of daily living (ADL) thru educating them ${ }^{(6)}$.

\section{The significance of the study:}

Rehabilitation of hand RA female patients is a crucial corner stone to the overall individuals' health, as they suffer from decline in hand strength and function. However, there is currently lacking of evidence investigating the relationship between the study variables among RA patients, particularly, in Egypt. This research will help to improve patients hand strength and ADL through implementing an intensive hand rehabilitation program.

\section{Aim of the Study}

This study aims to assess the effect of implementing a rehabilitation program on RA female patients' knowledge, hand strength and daily living activities.

\section{Research Hypothesis}

Hand and wrist Rheumatoid arthritis female patient's knowledge, hand strength and ADL improve after implementation of the intensive hand rehabilitation program.

\section{Materials and Method}

\section{Materials}

Design: A quasi-experimental research was used.

Setting: Data was collected from Rheumatology inpatient department and outpatient clinic of Assiut University Hospital, Egypt.

Subjects: A convenience sample of fifty adult female patients with hands and wrist RA.

Inclusion criteria: Patients' duration of disease ranges from three to five years, moderate to severe degree of disease. Only hands and wrist female patients who were free from severe cardiac disease (heart failure, recent myocardial infarction), Pulmonary disease, inflammatory or muscle disease or previous hand or arm injuries were involved.

Sample size calculation: Epi info-7 was selected to estimate the sample size as: Population size $=80$ / 3months, Expected frequency $=50 \%$, Acceptable error $=5 \%$, Confidence co efficient $=95 \%$ thus; Minimum sample size $=50$ patients.

Tools: Three tools were utilized for data collection to attain the study aims:

\section{Tool I: Health Assessment Interview Schedule}

This tool was developed to assess patients suffering from wrist and hand rheumatoid arthritis (RA). It comprises three parts: 
Part (1): Socio-demographic data which included patient's name, age, telephone number, level of education, occupation and disease duration.

Part (2): Patient knowledge questionnaire (PKQ). It was achieved by using Hill and Bird (PKQ) $(2007)^{(8)}$. It was adopted to measure the RA patients' knowledge as regards their disease (e.g. definition, causes, risk factors, complications, methods of diagnosis, treatments and its precautions). It contains 16 multiple choice questions. Scoring system: Answers were scored on 3 points Likert scale from correct and complete answer $(=2)$, to wrong answer or don't know $(=0)$. A total score of $75 \%$ and above was considered good knowledge, $50 \%$ to less than $75 \%$ was considered fair knowledge. While less than $50 \%$ score was considered poor knowledge

Part (3): Assessment of rheumatoid arthritis patient's Activity of daily living (ADL). This part was developed by the researchers to assess the effects of rheumatoid arthritis (RA) on patient's ability to perform ADL. It addressed eight categories; containing 28 multiple choice questions regarding (dressing, rising stairs, eating, walking, hygiene, reach, grip and common daily living activities). Scoring system: ADL was scored on a 5 point Likert scale from unable to do $(=4)$ to no difficult at all $(=0)$.

\section{Tool II: Michigan hand outcome Questionnaire (MHO)}

This adopted questionnaire design and factor analysis were confirmed by Chung B and Morris S., 2015. ${ }^{(9)}$ It was adopted to measure hand and wrist function of the studied patients. It includes 37 multiple choice questions, divided into: (1) Overall hand function (17 items). (2) Work performance and hands/wrists problem interference and amount of pain (10 items), and (3) Patients' satisfaction with hand function (10 items). Scoring system: overall hand function items were scored on fivepoint likert scale, very good $(=1)$ to very poor(=5), Pain interference with work performance scoring ranged from: always $(=1)$ to never $(=5)$. While satisfaction scoring was: dissatisfied (0), moderately satisfied (1) and very satisfied (2). The scoring became: from $1 \geq 40$ considered dissatisfaction, from $40 \geq 80$ denoted neutral responses and $80 \geq 120$ signified satisfaction.

\section{Tool III: Hand Grip Strength Test}

It was developed and tested for its validity in $2019^{(7)}$. It is a portable electronic scale; namely: grip strength test GST-2013® (fig.1). It aimed to evaluate the studied patients' hand grip strength after the intensive hand rehabilitation program implementation. The portable electronic scale specification is $\max .40 \mathrm{~kg} / \mathrm{min} .20 \mathrm{~g}$. It has a metallic hanger, stainless steel frame $12 \times 25 \mathrm{~cm}$ length and two metallic bars, upper and lower bar, that are covered with two pieces of sponge shielded by a piece of cloth. The portable electronic scale standby mode is at zero.
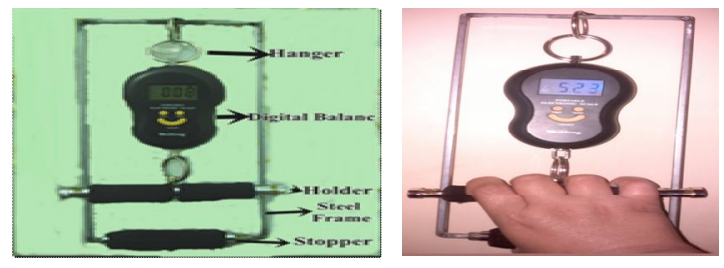

\section{Figure (1)}

\section{Method}

- Necessary approval was gained from the ethical committee from Faculty of Nursing, Alexandria University.

- An official permission was obtained from the head of the Rheumatology and Rehabilitation department at Assiut University hospital.

- The study tool (I) parts one and three, tool (III) were developed by the researchers based on recent review of literature $^{(2,5-8)}$. The tools' content validity was confirmed by 5 jury experts' in Medical-Surgical Nursing, Physiotherapy and Orthopedic fields. 
The required changes were introduced accordingly.

- A pilot study was conducted on $10 \%$ of the subjects, who met the inclusion criteria, to test the tool feasibility, applicability and clarity. Those patients were excluded from the study subjects. Data obtained from the pilot were analyzed and necessary modifications were done. Reliability of the tool was tested using Cronbach's Alpha test; reliability was (0.912).

- To fulfill the study aim, the hand strength rehabilitation program was illustrated by the researchers based on recent review of literature ${ }^{(2,3,5)}$ to demonstrate knowledge about RA as well as exercises important to improve hand grip strength

- Data collection: Patients were interviewed individually in order to collect necessary tools data prior and after program implementation. This interview took approximately 30-45 minutes for each patient to complete the scheduled interview questionnaires. Data was collected from December 2018 to April 2019.

- Plan of session: At initial interview session: Patient's identification and orientation about the importance of hand and wrist RA rehabilitation program. The program included information regarding simple anatomy of the hand and wrist, disease definition, incidence, causes, pathophysiology, signs and symptoms, diagnosis, pharmacological and nonpharmacological management and complication. The rehabilitation program also included core knowledge about rehabilitation definition, importance and its basic steps focusing on the rehabilitative exercises to cope with ADL and alleviate joint pain. Patients were interviewed to assess their knowledge, practices, and health related domains beside measuring how the disease affected their ADL. They were divided into small groups; each group contains 7-9 patients for the purpose of being repetitively trained about the taught rehabilitation wrist and hand exercise. The rehabilitation program was implemented in 4 sessions in addition to a preliminary session, each session lasted from 30-45 instructed to use warm water at night and early morning, for 15 minutes prior to performing exercise. After each discussion and feedback.

- This intensive rehabilitation program included hand strength exercises of a moderate intensity 3-5 times/day, three days/week, as well as stretching or ROM exercises at least once daily in addition to performing recreational activities can be beneficial through helping the patients to cope with disease process and everyday life problems.

- Also patients after sessions were encouraged to use the grip strength test scale GST-2013®, by catching the two bars by fist and press hard as possible patients and repeat this three times, then the researchers documented these readings.

- Program Evaluation: It was done immediately after program implementation (pre-test), after one month from the beginning of the program (pre/post 1) and three months thereafter (pre/post 2). Throughout the three months the researchers follow up the RA female patients, through meeting them individually (two to three times/month) at outpatient clinic to ensure that exercises were performed regularly at home. Tool 3 was used to collect three time average readings of pre-program implementation and three months post-program. 


\section{Ethical considerations:}

Oral consent was obtained from all patients after being informed about the nature, purpose and benefits of the study. Patients were also informed that involvement is voluntary and they have the right to withdraw at any time. The investigators emphasized that the participations' confidentiality and anonymity is assured through coding all of data that would be used for the research purpose only.

\section{Statistical Analysis}

Data were collected and fed into computer and analyzed by SPSS statistical analysis software and were tabulated through descriptive statistics in the form of frequencies and percentages. T-test was used for measuring knowledge gain ratio which was identified among pre/post1 and pre/post2 and for comparison of means; Ztest for proportion; Statistical significance was considered at $Z$ value $\leq 1.96^{*}$ and $\mathrm{Z} \leq 2.58^{* *}$. Correlation coefficient and high confidence limit (HCL) and low confidence limit (LCL) by mean of advanced statistical Analysis package (ASAP). Data reliability were paired e.g., intra-rater. Statistical significance was considered at $\mathrm{p}$. value $<0.05$.

\section{Results}

Findings of this study were presented in three sections; the first section included data related to the socio-demographic characteristic of patients (table 1). The second section comprised patients' frequency distribution in relation to the score values that indicate knowledge gain ratio after program application, common daily living activities, pain interference with work activities, as well as patients' satisfaction with hand function and instructions related to improving hands functioning (tables 2-6). The third section represents data related to correlation between hand grip strength pre and post hand strength exercises program finding (table 7).

Table (1) shows that nearly half of the studied patients $(48 \%)$ had their age ranging from 40 to 50 years; with mean of $40 \pm 9.34$. More than two third of them were house wives $(86 \%)$; with mean morning stiffness of $0.84 \pm 0.24$ ranging 0.5 to 1 hour. It was noted that Fifty six percent of the patients $(56 \%)$ were illiterate. As regards the duration of disease; the mean $4.3 \pm 0.76$ ranging between $3-5$ years and $(88 \%)$ of them were positive Rheumatic factor.

Table (2) illustrates a highly statistical significant difference $\left(\mathrm{P} \leq 0.01^{* *}\right)$ comparing pre/post1 and pre/post2 program evaluation; indicating improvements following the rehabilitation program among study subjects regarding RA knowledge. It was observable that knowledge gain rate among the study patients in pre /post-test (1) was more than gain in the pre/post-test (2) representing 1.20 and 0.99 respectively.

A highly significant difference $(\mathrm{p}<0.001)$ can be seen on sum knowledge mean score; where it was $(7.00 \pm 2.50)$ in pre-test and increased to $(23.88 \pm 4.64)$ in post 1 , with nearly the same significant difference in post $2(20.96 \pm 4.92)$.

Table (3) displays relation between the effect of hand rehabilitation program on the ADL mean score. It was observed that; a highly statistical significant difference throughout rehabilitation program was declared regarding common ADL total scores among study patients in post $1 \& 2$ $\left(\mathrm{Z} \leq 1.96^{*}\right.$ and $\left.\mathrm{Z} \leq 2.58^{* *}\right)$.

Table (4) reveals highly statistical improvements among study patients related to overall hand function noted in all hand functions in pre and post rehabilitation program $1 \& 2$, except for "sensation in hands, pick up coin, hold glass of water and close button of blouse"; which z-values remained insignificant in all assessment phases.

Table (5) illustrates highly statistical significant improvement related patient 
work performance, hands/wrists pain interference, in relation to "pain frequency and description", where ( $\mathrm{z}=6.40$ in post 1 and 4.8 in post 2$)$ and ( $\mathrm{z}=5$ in post 1 and 4 in post 2) respectively.

Table (6) reveals highly statistical improvement in patients' satisfaction with hand function as regards to pre and post rehabilitation program. It can observed that the item "acceptance of hand" remains insignificant in pre and post-tests $(\mathrm{z}=0.40$ in post1 and $\mathrm{z}=1.8$ in post 2), indicating improvements throughout the rehabilitation program phases.

Table (7) reveals a highly statistical improvement post rehabilitation program related to both hands. Where the right patients' hand mean \& SD pre-program compared to post three months was (6.70 \pm 3.66$),(9.66 \pm 4.02)$ respectively; where $(\mathrm{t}=5.34)$. Whereas; hand grip strength of the patients' left hand pre and post-program mean \& SD score was $(5.99 \pm 3.35)$, $(8.83 \pm 3.56)$ respectively; as $(\mathrm{t}=5.41)$ highly significant.

\section{Discussion}

Rheumatoid arthritis (RA) is a chronic inflammatory polyarthritis; that can cause persistent joint pain, damage and long-term hands and feet disability. Rheumatoid arthritis overall management goals are to prevent or control joint damage, maximize function and decrease pain ${ }^{(2,10)}$. Hand rheumatoid arthritis patients' education plays a significant role in order to expand their knowledge, health behavior and activities of daily living (ADL) ${ }^{(11)}$.

Regarding to patient's knowledge about $R A$, this study illustrated a highly statistical significant improvement in the post-test ${ }^{(1)}$. After one month of application program. This is in agreement with Ndosi et al. (2011), who reported in their meta-analysis that; the pooled effects of nurse-led care on rheumatoid arthritis outcome disease activity significantly improves patient knowledge and prognosis, where $(\mathrm{P}<0.001)^{(12)}$.
Recent studies pointed the effect of RA patient's education on improving their knowledge which influenced the ADL of those patients. This put burden on medical and nursing staff to provide the educational program in simple manner by using pictures and videos for positive knowledge and behavior modification in order to comply with their disease.

Schlenk et al. (2012), Ndosi and Adebajo 2015 stated that, chronic diseases patient education as RA is very important by means of enabling them to cope with the disease and treatments. Rheumatoid arthritis patient education is aimed to expand their knowledge and affect their health behavior positively. Although the increasing advances in disease management, which stops disease progress; poor RA patient adherence is significantly influenced by their disease education and its management ${ }^{(13,14)}$.

Even though there are new RA patients' medications, highlighted RA patients need to learn self-care skills so that they could cope at home with the disease symptoms and prevent complications (Joplin et al., $2015)^{(15)}$.

Nurses has to support patientse physical functioning by supporting them to perform minimal self-care actively (e.g., to sort their beds).

It was observed in the result that; knowledge gain in (pre/post 1) was more than gain rate in (pre/post 2) after three months from implementation of rehabilitation program. This could be due to the fact that RA patients need continuous education program regarding exercises program, pain management and stress follow up as a part of their routine treatment.

The current study findings related to patients' common daily living activities showed that patients had a higher score in pre-test indicating the worse daily activity living status, which decreased in (post1) by highly statistical significant difference; with also a highly statistical significance in (post 2) with a lesser extent. This points out that 
mobility, physical activity and ADL are affected by pain and deformity caused by the disease. Regarding social domain (social role and social activity); patients demonstrated an improvement in post 1 and 2 in relation to daily activities concerning "make abed, carry a bag or brief case and use transportation, also get a good night's sleep and deal with feelings of depression".

Whereas; if most of the studied women house held ADL were affected; this in turn will put them in apparent frustration.

These results agree with Etcho et al. (2017) and Ahmed \& Mostafa (2019) pointed out that the decrease in hand grip strength and hand dexterity lead to difficulty and pain during ADL performance. As painful joints, night pain, that is a significant problem, can lead to stress and worry; consequently sleeping problems appears. Also RA health functional domains can be affected by disease progress; but when patients be in an acceptable symptom state, they will have in particular less pain and better coping ${ }^{(7,16)}$.

These findings also agree with Maska, Anderson \& Michaud (2011) who stated that: measuring Rheumatoid Arthritis patient's functional capacity is a strong predictor for functional status in the disease progression, future disability and long-term RA mortality ${ }^{(17)}$.

In line with these findings results show that common daily activity in pre rehabilitation program approximately of items ranging on high confidence limit (HCL) due to the fact that these hand and wrist housewives RA patients depended on hands (dressing, grooming, eating, grip, hygiene...etc) on common daily activity. While after rehabilitation program approximately of items dropped off to below (HCL) indicating an improvements on patient's common daily living.

These results agree with Janoudi et al. (2013) who reported that most of rheumatoid arthritis cases were unable to dress, groom or walk and had serious difficulty in adaptation with these activities, added that alteration in bowel function was noted compared to the patient's usual elimination pattern. This in turn lead to many limitations for patients: social life, hobbies, everyday tasks, personal and social relationships, and physical contact ${ }^{(18)}$.

According to the study by Borenstein et al. (2015), chronic pain and negative emotions be existent in a circular correlation, each making the other worse. Thus RA patientse pain causes them emotional discomfort and is reported to decrease a person's health status satisfaction, restrict joint mobility and increase pain perception; predicting disability ${ }^{(19)}$.

In line with the finding of the present study that the majority of the studied patients were retired housewives. This is in agreement with Almoallim and Albaradi (2014) who reported that, the majority of the Saudi Arabian's who are affected with RA were housewives. Explaining that; nearly one-half of RA working patients during their disease exacerbation were retired, due to disease disability $^{(11)}$.

Also, Janoudi et al. (2013) stated that most of his study RA female patients suffered reduced work ability and poorer satisfaction. The inability to carry out daily tasks with ease almost certainly contributes to deficit in psychological well-being. This influences of female patients' mood and self-esteem. Female have more difficulties than male, because they have the responsibility for housework and childcare $^{(18)}$.

Thus, rheumatology nurses should focus on increasing RA patients ${ }^{\mathrm{ee}}$ knowledge, parallel to improving their psychological status by teaching them how to manage their symptoms which increase their disease satisfaction (Schlenk et al., 2012) ${ }^{(13)}$.

Regarding to work performance and hands/wrists problem interference and amount of pain, in the present study findings there were highly statistical significant improvement in hand and wrists pain during 
work performance post 2 after three month of application of program, which $Z=4$ $(\mathrm{Z} \leq 2.58 * *)$ but is not to the desired image. This might be due to the fact that knowledge are easily forgotten, but multi-sessions exercises teaching are memorized, so it will be usefulness in alleviating hands and wrist pain after being enforced to continue the exercises at home.

It is well known that grip strength is one of the predictors for hand function. It can be measured objectively, quickly and frequently. As regard the improvement in patients' hand grip strength, the present study illustrated a significant improvements in the studied patients, which was assessed through using grip strength test GST-2013®, after performing intensive hand exercises three times/day for three consecutive months, in addition of application of warm water at night time and early morning.

This is in line with Kong et al. (2014) who stated that hand Grip exercise significantly increased the strength of tip pinch and palmar pinch compared. However, resistance exercise can significantly improve hand function by increasing blood flow volume and muscle contractility ${ }^{(20)}$.

Habibi (2013) and Ellegaard et al. (2019) stated that RA women need hands to cook, clean, type, and do just about everything else; Grip and pinch strength are reflecting hand function, general weakness, physical activities and muscle disability ${ }^{(21,22)}$.

Also, other studies reported that; hand exercise program is more effective in improving hand function and ADL ability in patients with RA-related impaired hand function. The improvement was even more pronounced after 6 weeks, leading to better hand strength and function ${ }^{(23,24)}$.

Strength of this study is that the intensive rehabilitation program was patient tailored, reflecting clinical nursing practice, and intended to ensure the delivery of exercise. It is designed to meet individual needs and significantly improves hand function and activity daily living in RA patients.

\section{Conclusion}

Accordingly, hand and wrist rheumatoid arthritis female patients who received the hand and wrist intensive rehabilitation training; had a significant improvement in their knowledge, hand strength and ADL as well as marked decrease joint pain especially at the morning after implementation of the intensive hand rehabilitation program by the researchers

As well in line with the hypothesis, the studied hand and wrist RA patients illustrated apparent improvement in their hands function and grip strength after 8 weeks of intensive hand exercises program.

\section{Recommendations}

- It was recommended to establish a planned continuous rehabilitation program in the rheumatology and rehabilitation unit outpatient clinics to ensure lower patients' disease remission.

- Written simple pictured booklet and pamphlets about RA and its management demonstrated (including exercises for hands, wrist) should be provided and available for patients.

- Explore the relation between exercise protocols and participant adherence. Also a similar replicated study on the effect of received exercise program on patients with hands and wrist post-burn plastic surgery is recommended. 
Table (1): Socio-demographic characteristics of patients with Rheumatoid Arthritis hand and wrist $(\mathrm{n}=\mathbf{5 0})$

\begin{tabular}{|c|c|c|}
\hline Socio-demographic characteristics & Frequency & Percent \\
\hline \multicolumn{3}{|l|}{ Age (years) } \\
\hline$<40$ & 20 & 40.0 \\
\hline 40 to less than 50 & 24 & 48.0 \\
\hline 50 less than 60 & 6 & 12.0 \\
\hline Mean \pm SD & \multicolumn{2}{|c|}{$40 \pm 9.34$} \\
\hline \multicolumn{3}{|l|}{ Duration disease/Year } \\
\hline Mean \pm SD & \multicolumn{2}{|c|}{$4.3 \pm 0.76$} \\
\hline \multicolumn{3}{|l|}{ Morning stiff/ hrs } \\
\hline Mean \pm SD & \multicolumn{2}{|c|}{$0.84 \pm 0.24$} \\
\hline \multicolumn{3}{|l|}{ Rheumatic Factor } \\
\hline Negative & 6 & 12.0 \\
\hline Positive & 44 & 88.0 \\
\hline \multicolumn{3}{|l|}{ Occupation } \\
\hline Housewife & 43 & 86.0 \\
\hline Retired housewives & 36 & 38.7 \\
\hline Manual work & 2 & 4.00 \\
\hline Clerical work & 5 & 10.0 \\
\hline \multicolumn{3}{|l|}{ Level of education } \\
\hline University level & 4 & 8.0 \\
\hline Elementary level & 8 & 16.0 \\
\hline Read and write & 10 & 20.0 \\
\hline Illiterate & 28 & 56.0 \\
\hline
\end{tabular}

Table (2): Assessment patient's knowledge and common daily activity living practice regard RA; pre, immediate (post-test 1) and three months after application of the program (post 2)

\begin{tabular}{|c|c|c|c|c|c|c|c|c|c|}
\hline \multirow[b]{2}{*}{ Knowledge items } & \multirow{2}{*}{$\frac{\text { Pre }}{\text { Mean } \pm \text { SD }}$} & \multirow{2}{*}{$\frac{\text { Post1 }}{\text { Mean } \pm \text { SD }}$} & \multicolumn{2}{|c|}{ t-test } & \multirow{2}{*}{$\begin{array}{c}\text { Post2 } \\
\text { Mean } \pm \text { SD }\end{array}$} & \multicolumn{2}{|c|}{ t-test } & \multicolumn{2}{|c|}{ Gain rate } \\
\hline & & & t-value & sig. $p$ & & t-value & sig. p & $\begin{array}{c}\text { pre/pos } \\
\text { t } 1\end{array}$ & $\begin{array}{c}\text { pre/ } \\
\text { prost } 2\end{array}$ \\
\hline Definition of RA & $0.00 \pm 0.00$ & $1.84 \pm 0.03$ & 24.59 & $<0.001$ & $1.64 \pm 0.49$ & 16.74 & $<0.001$ & 1.84 & 1.64 \\
\hline Effect of RA & $0.36 \pm 0.49$ & $1.72 \pm 0.46$ & 10.66 & $<0.001$ & $1.64 \pm 0.49$ & 7.60 & $<0.001$ & 1.51 & 1.42 \\
\hline Causes of RA & $0.64 \pm 0.49$ & $1.20 \pm 0.71$ & 3.65 & 0.001 & $1.00 \pm 0.00$ & 3.67 & 0.001 & 0.69 & 0.44 \\
\hline Blood test for RA & $1.48 \pm 0.77$ & $1.84 \pm 0.62$ & 1.74 & Ns & $2.00 \pm 0.00$ & 3.38 & 0.003 & 0.87 & 1.26 \\
\hline Diet for RA & $0.20 \pm 0.41$ & $1.84 \pm 0.37$ & 16.74 & $<0.001$ & $1.40 \pm 0.76$ & 5.55 & $<0.001$ & 1.73 & 1.27 \\
\hline $\begin{array}{l}\text { Side effect anti } \\
\text { inflammatory }\end{array}$ & $0.46 \pm 0.87$ & $1.60 \pm 0.82$ & 4.80 & $<0.001$ & $1.68 \pm 0.75$ & 5.20 & $<0.001$ & 1.31 & 1.40 \\
\hline Pain medicine & $0.64 \pm 0.49$ & $1.40 \pm 0.50$ & 8.72 & $<0.001$ & $1.44 \pm 0.54$ & 8.00 & $<0.001$ & 0.94 & 0.99 \\
\hline Benefit of exercises & $0.48 \pm 0.77$ & $1.68 \pm 0.48$ & 5.55 & $<0.001$ & $1.40 \pm 0.76$ & 3.33 & 0.003 & 1.39 & 1.07 \\
\hline $\begin{array}{l}\text { Common exercises for } \\
\text { RA }\end{array}$ & $0.16 \pm 0.37$ & $1.56 \pm 0.51$ & 14.00 & $<0.001$ & $1.28 \pm 0.46$ & 16.88 & $<0.001$ & 1.46 & 1.17 \\
\hline Practice and stiff joint & $1.00 \pm 0.00$ & $1.48 \pm 0.51$ & 4.71 & $<0.001$ & $1.00 \pm 0.71$ & 0.00 & ns & 0.72 & 0.00 \\
\hline $\begin{array}{l}\text { Dealing wit sore and } \\
\text { stiff joint }\end{array}$ & $0.12 \pm 0.33$ & $1.28 \pm 0.75$ & 10.15 & $<0.001$ & $1.48 \pm 0.77$ & 6.83 & $<0.001$ & 1.20 & 1.40 \\
\hline Protect joint strain & $0.28 \pm 0.61$ & $1.40 \pm 0.71$ & 6.35 & $<0.001$ & $1.28 \pm 0.89$ & 3.87 & $<0.001$ & 1.21 & 1.08 \\
\hline Daily activity & $0.32 \pm 0.75$ & $0.96 \pm 1.02$ & 2.55 & 0.018 & $0.88 \pm 1.01$ & 2.75 & 0.032 & 0.70 & 0.61 \\
\hline Save energy & $0.80 \pm 0.28$ & $1.48 \pm 0.51$ & 10.84 & $<0.001$ & $0.75 \pm 0.72$ & 4.24 & $<0.001$ & 0.91 & -0.07 \\
\hline Protect joints & $0.00 \pm 0.00$ & $0.84 \pm 0.37$ & 11.22 & $<0.001$ & $0.84 \pm 0.37$ & 6.53 & $<0.001$ & 0.84 & 0.84 \\
\hline High risk for RA & $0.76 \pm 0.45$ & $1.36 \pm 0.49$ & 5.20 & $<0.001$ & $1.24 \pm 0.66$ & 4.10 & $<0.001$ & 0.78 & 0.63 \\
\hline Sum & $7.00 \pm 2.50$ & $23.88 \pm 4.64$ & 17.04 & $<0.001$ & $20.96 \pm 4.92$ & 12.99 & $<0.001$ & 1.20 & 0.99 \\
\hline
\end{tabular}

$P>0.05 \quad N S$, Statistically significant at $(*) \quad P \leq 0.05 \quad$ Statistically highly significant at $(* *), P \leq 0.01$ 
Hand Exercise Program, Daily Living Activity, Rheumatoid Arthritis Patients

Table (3): Common daily activity living scores obtained by patients; pre, immediately after and 3 months after program implementation

\begin{tabular}{|c|c|c|c|c|c|c|c|c|c|c|}
\hline \multirow{2}{*}{ Category } & \multirow{2}{*}{\multicolumn{3}{|c|}{ Items }} & \multirow{3}{*}{$\begin{array}{l}\text { Pre } \\
0.64 \\
\end{array}$} & \multirow{3}{*}{$\begin{array}{c}\text { Post } 1 \\
0.48\end{array}$} & \multirow{3}{*}{$\begin{array}{c}\text { Post } 2 \\
0.48\end{array}$} & \multicolumn{4}{|c|}{ Z-test } \\
\hline & & & & & & & \multicolumn{2}{|c|}{ Pre/ Post 1} & \multicolumn{2}{|c|}{ Before/ Post 2} \\
\hline \multirow{28}{*}{ 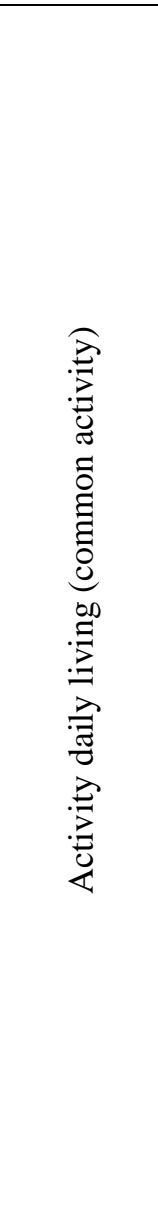 } & \multirow{2}{*}{ 1- Dressing \& Grooming } & \multirow[t]{2}{*}{1} & $\mathrm{a}$ & & & & 4.00 & $* *$ & 4.00 & $* *$ \\
\hline & & & $\mathrm{b}$ & 0.59 & 0.46 & 0.48 & 3.30 & $* *$ & 2.80 & $* *$ \\
\hline & \multirow{2}{*}{ 2- Raising stairs } & \multirow{2}{*}{2} & $\mathrm{a}$ & 0.66 & 0.53 & 0.53 & 3.40 & $* *$ & 3.40 & $* *$ \\
\hline & & & $\mathrm{b}$ & 0.72 & 0.51 & 0.54 & 5.20 & $* *$ & 4.60 & $* *$ \\
\hline & \multirow{4}{*}{ 3- Eating } & \multirow{4}{*}{3} & $\mathrm{a}$ & 0.67 & 0.55 & 0.58 & 3.00 & $* *$ & 2.20 & $*$ \\
\hline & & & $\mathrm{b}$ & 0.62 & 0.50 & 0.50 & 2.80 & $* *$ & 2.80 & $* *$ \\
\hline & & & $\mathrm{c}$ & 0.80 & 0.45 & 0.45 & 8.80 & $* *$ & 8.80 & $* *$ \\
\hline & & & $\mathrm{d}$ & 0.45 & 0.58 & 0.55 & 3.20 & $* *$ & 2.60 & $* *$ \\
\hline & \multirow{3}{*}{ 4-Walking } & \multirow{3}{*}{4} & $\mathrm{a}$ & 0.66 & 0.39 & 0.38 & 6.80 & $* *$ & 7.20 & $* *$ \\
\hline & & & $\mathrm{b}$ & 0.67 & 0.63 & 0.59 & 1.00 & ns & 2.00 & $*$ \\
\hline & & & $\mathrm{c}$ & 0.71 & 0.57 & 0.55 & 3.60 & $* *$ & 4.00 & $* *$ \\
\hline & \multirow{5}{*}{ 5- Hygiene } & \multirow{5}{*}{5} & $\mathrm{a}$ & 0.78 & 0.60 & 0.62 & 4.40 & $* *$ & 4.00 & $* *$ \\
\hline & & & $\mathrm{b}$ & 0.85 & 0.67 & 0.63 & 4.40 & $* *$ & 5.40 & $* *$ \\
\hline & & & $\mathrm{c}$ & 0.79 & 0.77 & 0.72 & 0.55 & $\mathrm{~ns}$ & 1.80 & Ns \\
\hline & & & $\mathrm{d}$ & 0.66 & 0.70 & 0.70 & 1.00 & ns & 1.00 & Ns \\
\hline & & & $\mathrm{e}$ & 0.85 & 0.58 & 0.55 & 6.80 & $* *$ & 7.40 & $* *$ \\
\hline & \multirow{2}{*}{ 6- Reach } & \multirow{2}{*}{6} & $\mathrm{a}$ & 0.58 & 0.58 & 0.61 & 0.20 & $\mathrm{~ns}$ & 0.60 & $\mathrm{Ns}$ \\
\hline & & & $\mathrm{b}$ & 0.78 & 0.48 & 0.46 & 7.40 & $* *$ & 8.00 & $* *$ \\
\hline & \multirow{3}{*}{ 7- Grip } & \multirow{3}{*}{7} & $\mathrm{a}$ & 0.75 & 0.58 & 0.60 & 4.40 & $* *$ & 3.80 & $* *$ \\
\hline & & & $\mathrm{b}$ & 0.74 & 0.50 & 0.54 & 6.00 & $* *$ & 5.20 & $* *$ \\
\hline & & & $\mathrm{c}$ & 0.70 & 0.59 & 0.62 & 2.60 & $* *$ & 1.80 & Ns \\
\hline & \multirow{7}{*}{ 8- Activities } & \multirow{7}{*}{8} & $\mathrm{a}$ & 0.74 & 0.53 & 0.53 & 5.40 & $* *$ & 5.40 & $* *$ \\
\hline & & & $\mathrm{b}$ & 0.68 & 0.48 & 0.52 & 5.00 & $* *$ & 4.00 & $* *$ \\
\hline & & & $\mathrm{c}$ & 0.56 & 0.58 & 0.55 & 0.60 & $\mathrm{~ns}$ & 0.20 & Ns \\
\hline & & & $\mathrm{d}$ & 0.64 & 0.50 & 0.50 & 3.60 & $* *$ & 3.60 & $* *$ \\
\hline & & & $\mathrm{e}$ & 0.88 & 0.54 & 0.54 & 8.60 & $* *$ & 8.60 & $* *$ \\
\hline & & & $\mathrm{f}$ & 0.90 & 0.58 & 0.59 & 8.20 & $* *$ & 7.80 & $* *$ \\
\hline & & & $\mathrm{g}$ & 0.82 & 0.62 & 0.65 & 5.00 & $* *$ & 4.20 & $* *$ \\
\hline
\end{tabular}

$Z>1.96$ ns=not significant Statistically significant at $Z \leq 1.96 * \quad Z \leq 2.58 * *$ post 1(after one month) post 2 (after 3 months)

Table (4): The overall hand functions of hand and wrist RA patients; pre and immediately and 3 months after rehabilitation program implementation $($ no=50)

\begin{tabular}{|l|l|c|c|c|c|c|c|c||}
\hline & Hand functions items & Pre & Post 1 & z value & Sig. & Post 2 & z value & Sig. \\
\hline 1 & Hand work & 0.7 & 0.58 & 3.50 & $* *$ & 0.51 & 5.25 & $* *$ \\
\hline 2 & Fingers move & 0.5 & 0.44 & 2.00 & $*$ & 0.38 & 3.40 & $* *$ \\
\hline 3 & Wrist move & 0.6 & 0.49 & 3.60 & $* *$ & 0.41 & 5.55 & $* *$ \\
\hline 4 & Strength hand & 0.7 & 0.66 & 1.00 & Ns & 0.59 & 2.60 & $* *$ \\
\hline 5 & Sensation (feeling) in hand & 0.5 & 0.49 & 1.20 & Ns & 0.49 & 1.20 & Ns \\
\hline 6 & Turn a door knob. & 0.8 & 0.67 & 3.20 & $* *$ & 0.67 & 3.20 & $* *$ \\
\hline 7 & Pick up a coin. & 0.7 & 0.66 & 1.60 & Ns & 0.66 & 1.60 & Ns \\
\hline 8 & Hold a glass of water. & 0.4 & 0.38 & 1.40 & Ns & 0.37 & 1.80 & Ns \\
\hline 9 & Turn a key in the lock. & 0.8 & 0.65 & 5.00 & $* *$ & 0.65 & 5.00 & $* *$ \\
\hline 10 & Hold a frying pan. & 0.8 & 0.65 & 3.00 & $* *$ & 0.62 & 3.80 & $* *$ \\
\hline 11 & Open a tight or new Jar. & 0.9 & 0.7 & 5.00 & $* *$ & 0.69 & 5.40 & $* *$ \\
\hline 12 & Button a shirt or blouse. & 0.8 & 0.6 & 4.00 & $* *$ & 0.6 & 4.00 & $* *$ \\
\hline 13 & Eat with a knife and fork. & 0.6 & 0.58 & 1.20 & Ns & 0.58 & 1.20 & Ns \\
\hline 14 & Carry a grocery bag. & 0.8 & 0.68 & 3.40 & $* *$ & 0.68 & 3.40 & $* *$ \\
\hline 15 & Wash dishes. & 0.5 & 0.44 & 2.20 & $*$ & 0.44 & 2.20 & $*$ \\
\hline 16 & Wash your hair. & 0.7 & 0.59 & 3.60 & $* *$ & 0.62 & 3.00 & $* *$ \\
\hline 17 & Tie shoelaces or knots & 0.7 & 0.56 & 3.60 & $* *$ & 0.57 & 3.40 & $* *$ \\
\hline
\end{tabular}


Table (5): The work performance and hands/ wrists problem interference with amount of pain pre and immediately and 3 months after rehabilitation program implementation (no=50)

\begin{tabular}{|c|c|c|c|c|c|c|c|}
\hline Items & Pre & $\begin{array}{c}\text { Post } \\
1\end{array}$ & $\begin{array}{c}\mathbf{Z} \\
\text { value }\end{array}$ & Sig. & $\begin{array}{c}\text { Post } \\
2\end{array}$ & $\begin{array}{c}\mathbf{Z} \\
\text { value }\end{array}$ & Sig. \\
\hline 1. How unable to do work because hand problems & 0.46 & 0.59 & 3.35 & $* *$ & 0.51 & 1.40 & Ns \\
\hline 2. Shorten in work day because hand problem & 0.38 & 0.54 & 4.00 & ** & 0.54 & 4.00 & $* *$ \\
\hline 3. How often did you have to take easy at work. & 0.52 & 0.65 & 3.25 & $* *$ & 0.61 & 2.20 & $*$ \\
\hline $\begin{array}{l}\text { 4. How often did you accomplish less in work because hand } \\
\text { problem }\end{array}$ & 0.48 & 0.58 & 2.40 & $*$ & 0.58 & 2.60 & $* *$ \\
\hline 5. How often did you take longer to do tasks in work. & 0.26 & 0.44 & 4.60 & $* *$ & 0.44 & 4.60 & $* *$ \\
\hline $\begin{array}{l}\text { 6. How often did have morning pain in hands/ wrists that interfere } \\
\text { with daily activities }\end{array}$ & 0.28 & 0.54 & 6.40 & $* *$ & 0.47 & 4.80 & $* *$ \\
\hline 7. Describe the pain in hands/ wrists interfere with daily activities & 0.72 & 0.52 & 5.00 & ** & 0.56 & 4.00 & $* *$ \\
\hline 8. How often did the pain interfere with sleep & 0.33 & 0.53 & 5.00 & $* *$ & 0.54 & 5.40 & $* *$ \\
\hline 9. How often did the pain interfere with daily activity & 0.38 & 0.6 & 5.60 & *** & 0.58 & 5.00 & $* *$ \\
\hline 10. How often did the pain make unhappy & 0.35 & 0.66 & 7.60 & *** & 0.59 & 6.00 & $* *$ \\
\hline
\end{tabular}

Table (6): Patient satisfaction with hand function; pre and immediately and 3 months after rehabilitation program implementation $($ no $=50)$

\begin{tabular}{|c|c|c|c|c|c|c|c|}
\hline Items & $\overline{\text { Pre }}$ & Post 1 & z value & $\overline{\text { Sig. }}$ & Post 2 & $\mathrm{z}$ value & Sig. \\
\hline 1. I was satisfied with the appearance of my hand & 0.67 & 0.5 & 4.20 & $* *$ & 0.5 & 4.40 & $* *$ \\
\hline $\begin{array}{l}\text { 2. The appearance of my hand sometimes made } \\
\text { me un happy }\end{array}$ & 0.57 & 0.48 & 2.25 & $*$ & 0.5 & 1.50 & Ns \\
\hline 3. The appearance of hand made me depressed & 0.59 & 0.48 & 2.75 & $* *$ & 0.5 & 2.00 & $* *$ \\
\hline $\begin{array}{l}\text { 4. The appearance of hand interfered with normal } \\
\text { social activities }\end{array}$ & 0.5 & 0.48 & 0.40 & Ns & 0.6 & 1.80 & Ns \\
\hline 5. Overall function of hand & 0.48 & 0.62 & 3.40 & $* *$ & 0.6 & 0.58 & Ns \\
\hline 6. Motion of the fingers in hand & 0.5 & 0.64 & 3.50 & $* *$ & 0.6 & 2.00 & $*$ \\
\hline 7. Motion of wrist & 0.55 & 0.64 & 2.25 & $*$ & 0.5 & 1.00 & Ns \\
\hline 8. Strength level of hand & 0.48 & 0.6 & 3.00 & $* *$ & 0.6 & 3.00 & $* *$ \\
\hline 9. Morning Pain level of hand & 0.62 & 0.72 & 2.60 & $* *$ & 0.7 & 2.60 & $* *$ \\
\hline 10. Sensation (feeling) your hand & 0.46 & 0.58 & 3.00 & $* *$ & 0.6 & 3.00 & $* *$ \\
\hline
\end{tabular}

$Z>1.96$ ns=not significant $\quad$ Statistically significant at $Z \leq 1.96 * Z \leq 2.58 * *$ post I(after one month) post 2 (after 3 months)

Table (7): Hand grip strength measurement pre and post hand strength rehabilitation program (no=50)

\begin{tabular}{||l|c|c|c|c|c|c||}
\hline \hline \multirow{2}{*}{ Hand grip strength measurements } & \multicolumn{2}{|c|}{ Pre } & \multicolumn{2}{c|}{ Post } & \multicolumn{2}{|c|}{ t-test } \\
\cline { 2 - 8 } & Mean & SD & Mean & SD & $\begin{array}{c}\text { t- } \\
\text { value }\end{array}$ & Sign. \\
\hline Right hand $(\mathrm{KG})$ & 6.70 & 3.66 & 9.66 & 4.02 & 5.34 & $* *$ \\
\hline Left hand $(\mathrm{KG})$ & 5.99 & 3.35 & 8.83 & 3.56 & 5.41 & $* *$ \\
\hline$P\left(0.04^{*}, 0.5^{* *}\right)$ & & & & & & \\
\hline
\end{tabular}




\section{References}

1. The Johns Hopkins Arthritis Center USA. 2019. Available at: https://www.hopkinsarthritis.org/arthritisresearch/ Last updated 2019.

2. Hinkle J. \& Cheever K. Brunner's Textbook of Medical-Surgical Nursing. 14th Edition. Philadelphia: Wolter Klawer. 2019.

3. World Health Organization: Chronic diseases and health promotion. 2018. Available at: https://www.who.int/chp/topics/rheumatic/e n/ Last updated 2019.

4. Nakano H1, Houraiya $\mathrm{K}$, Tanimura $\mathrm{H}$, Saura R. Rehabilitation therapy according to the disease condition and functional status of the patients with rheumatoid arthritis Nihon Rinsho. 2013, 71(7):1281-6.

5. Ramiro S, Sepriano A, Chatzidionysiou K, et al. Safety of synthetic and biological DMARDs: a systematic literature review informing the 2016 update of the EULAR recommendations for management of rheumatoid arthritis. BMJ. 2017, 76:11011136.

6. American College of Rheumatology Subcommittee on Rheumatoid Arthritis: Guidelines for the management of rheumatoid arthritis. 2019. Available at: https://www.rheumatology.org/PracticeQuality/Clinical-Support/Clinical-PracticeGuidelines/Rheumatoid-Arthritis.

7. Ahmed G., Mostafa N. Comparative study between two different hand squeezing exercises in improving hand grip strength for patients underwent arteriovenous fistula surgery. International Journal of Advance Research in Nursing. 2019, 2 (1): 95-100.

8. Hill, H. Bird. Patient knowledge and misconceptions of osteoarthritis assessed by a validated self-completed knowledge questionnaire (PKQ-OA). Journal of Rheumatology, 2007; 46: 5, 796-800.

9. Chung BT, Morris SF. Confirmatory factor analysis of the Michigan Hand Questionnaire. Ann Plast Surg. 2015; 74(2):176-81.
10. Annual Report: Past, Present and Future. Arthritis Foundation National Office. Atlanta. USA. 2018. Available at: https://www.arthritis.org/about-us/annualreport/archived-annual-reports.php Last updated 2019.

11. Almoallim H, Albaradi L. Rheumatoid arthritis in Saudi Arabia. Saudi Med J; 2014; 35 (12): 1442-1454.

12. Ndosi M., Vinall K., Hale C., Bird H., Hill $\mathrm{J}$. The effectiveness of nurse-led care in people with rheumatoid arthritis: A systematic review. International Journal of Nursing Studies, 2011; 48 (5). 642-654.

13. Schlenk E., Starz R., Levesque M., Baker N., Rogers J. Understanding Function in RA: The Nurse's Role in Patient Evaluation. 2012. 29:315-20

14. Ndosi M. \& Adebajo A. Patient education in rheumatoid arthritis: is the needs-based approach the way forward? Clin Rheumatol. 2015; 34:1827-1829.

15. Joplin, S., van der Zwan, R., Joshua, F., Wong, P. K. Medication adherence in patients with rheumatoid arthritis: the effect of patient education, health literacy, and musculoskeletal ultrasound. Bio. Med. research international, 2015; Article ID: 150658 .

16. Etcheto A., Puyraimond-Zemmour E., Fautrel B., Balanescu A., Wit M., Heiberg T., Otsa K., Kvien T., Dougados M. Gossec L. Associations between Five Important Domains of Health and the Patient Acceptable Symptom State in Rheumatoid Arthritis and Psoriatic Arthritis: A Cross - Sectional Study of 977 Patients. Arthritis Care \& Research, 2017; 69 (10): 1504-1509.

17. Maska L., Anderson J., Michaud K. Measures of Functional Status and Quality of Life in Rheumatoid Arthritis. Arthritis Care \& Research, 2011; 63 (11): S4-S13.

18. Janoudi N1, Almoallim H, Husien W, Noorwali A, Ibrahim A. Work ability and work disability evaluation in Saudi patients with rheumatoid arthritis. Special emphasis on work ability among housewives. Saudi Med J. 2013; 34(11):1167-72. 
19. Borenstein D., Dodge C., Williams-Judge S. Manage your pain, Causes of pain and tips for taking control. The Arthritis Foundation. 2015. Available at: https://www.arthritis.org/

20. Kong S., Lee K., Kim J., and Jang S. The Effect of Two Different Hand Exercises on Grip Strength, Forearm Circumference, and Vascular Maturation in Patients Who Underwent Arteriovenous Fistula Surgery. Ann Rehabil Med. 2014; 38(5): 648-657.

21. Habibi E, Kazemi M, Dehghan H, Mahaki B, Hassanzadeh A. Hand grip and pinch strength: Effects of workload, hand dominance, age, and Body Mass Index. Pak J Med Sci. 2013; 29(1):363-367.
22. Ellegaard K., Bülow C., Røpke A., BartholdyC., Hansen I., Henriksen M. and Wæhrens E. Hand exercise for women with rheumatoid arthritis and decreased hand function: an exploratory randomized controlled trial. Arthritis Research \& Therapy, 2019; 21:158.

23. Alison Hammond, Yeliz Prior, The effectiveness of home hand exercise programmes in rheumatoid arthritis: a systematic review, British Medical Bulletin, 119: 1, 2016, 49-62, DOI: https://doi.org/10.1093/bmb/ldw024

24. Hand exercises improve function in rheumatoid arthritis patients. 2014. Retrieved September 2019. Available at: https://medicalxpress.com/news/2014-10function-rheumatoid-arthritispatients. 